\title{
White Supremacy and Libraries
}

\section{Thoughts Around the Campfire}

Matt Ostercamp, North Park University

ABSTRACT: Shortly after the murder of George Floyd in May of 2020, I came across the 1872 painting American Progress. In this painting, westward expansion is being led by a large floating white woman with a schoolbook in one arm and telegraph wires in the other. The Indigenous inhabitants of the West cower before this apparition. It is indeed a haunting image. In this paper, I explore the legacy of Enlightenment constructs of civilized/savage in the operations of academic libraries. I then introduce Indigenous authors Leanne Betasamosake Simpson and Shawn Wilson who offer some alternatives to Western knowledge practices. Finally, I conclude by reflecting on what theological librarians can contribute to our professional conversation on White supremacy.

The murder of George Floyd in May 2020 occasioned conversations around the world on racism and race-based oppression. In the Brandel Library at North Park University, we asked each other about the impact of racism on library practice. Throughout that summer, different staff members led conversations on this topic through the lens of their particular expertise in archives, instruction, and collections. The idea for this paper was birthed in those conversations, and I'm excited to invite you to join us in reflecting on the possible connections between libraries and White supremacy.

I also want to acknowledge my debt to North Park psychology student and library office manager Charis Ivanoff. Cher, who is Native Alaskan, graciously answered my many questions to her about her experiences with Indigenous culture and joined me in reading the works of Indigenous scholars referenced below. I came into this work with very little previous experience with the culture and practices of the Indigenous peoples of North America, and Cher's guidance was very valuable. 


\section{CAMPFIRES}

Have you ever sat around a campfire after a long summer day? Have you heard the wood crackle? Felt the sting of the smoke in your eyes? Watched the sparks ascend towards the stars above? As indicated by the subtitle, I invite you to conjure those late-night campfires as the imagined setting for this paper. I invoke the campfire first because it is a place of reflection on our connections to the thousands of years of human history that have come before us. When we look into the coals or turn our gaze to the stars, we are sharing experiences with our distant ancestors. Here I experience both the humbling thought that our chapter is part of a much larger story and also awe that the journey has led to this current moment and a responsibility to those who came before.

But a campfire is more than this. A campfire is a place for guitars, singing, and laughing at funny stories. It is a place we can connect with old friends and discover new friends. There is an easy intimacy around the campfire where we can lose ourselves in community. Can you think of a goofy campfire song you've shared with friends? I invite you to remember the friendly warmth of the fire as you read.

Mostly though, I invoke the campfire because it provides a setting where we commonly lower our defenses and are allowed to question cherished assumptions. The campfire is liminal space that invites wonder and curious speculation about ideas that linger on the periphery of consciousness. It is the principal place where we tell ghost stories and explore what haunts us. I'm inviting you to join me in front of the flickering flames, to momentarily suspend your usual assumptions. I'm inviting you to a ghost story.

\section{CIVILIZATION AND SAVAGES}

"Because Western academic libraries in particular emerged from Enlightenment-derived epistemology and are premised on Euro- and Christian-centric knowledge structures, libraries have unwittingly participated in and supported this legacy of imperialism historically and contemporarily." (Gohr 2017, 43)

Our exploration of racism and libraries in the summer of 2020 led me to the above quote in Michelle Gohr's article on decolonization and libraries. As I read this quote, I could feel my body tense, and I wanted to argue with the premise and dismiss the conclusion. Libraries are ancient, I thought. Libraries are good, I said. Maybe 
that is your reaction as well. But I couldn't let it go. As I kept thinking about it, I had to admit that it is likely that modern librarianship is connected to modern epistemology. An epistemology that came into its own in the wake of the "Age of Discovery" and flourished during the era of the Atlantic slave trade and European colonization.

At its best, the Enlightenment was bold, confident, and willing to challenge old assumptions. But when I read seventeenth- and eighteenth-century European intellectuals, I find them often more than a little smug, a little too self-important and haughty. They were convinced that their intellectual and cultural project was superior to the work of their predecessors, and one often finds claims of math over myth, science over superstition, reason over passion. In eighteenth-century Britain, "polite society" was championed over the rank "enthusiasm" of religious and cultural others such as the Catholic Jacobin Highland clans. Ultimately the rational, scientific, and polite cultural project claimed the title of civilization and branded those it found superstitious and engaging in crude passions as the savage.

Although we no longer speak of bringing civilization to the "savages" of the world, as one once did, it is interesting to me how the civilized/savage dichotomy continues to live on in racial tropes such as the angry black woman. But does it also live on in modern libraries? Could one make a case that libraries are monuments of scientific modernism?

When Gohr writes that libraries "emerged from Enlightenmentderived epistemology," I think of Newton's universal laws, Bacon and Locke's empiricism, and the rationalism of Descartes and Spinoza, and I find resonance with libraries' attempts to maintain neutrality, and aspirations to collect and catalog all points of view on all subjects. There seems to be something fundamentally modern and secular about libraries' refusal to judge texts based on conformity to creeds and ideology. Finally, common behavioral norms of silent, solitary text-based study traditionally associated with libraries bear a resemblance at least to the celebrated norms of polite society in contrast to the uncouth mores of the enthusiasts.

Now I'm not here claiming that I've made the case that libraries are connected to Enlightenment thought, let alone imperialism and colonialism. But haunted by the thought that there may be a connection, this reflection on the historic dichotomy between civilized and savage did little to assuage my fear, and since this is a ghost story, it is time to meet the ghost. 


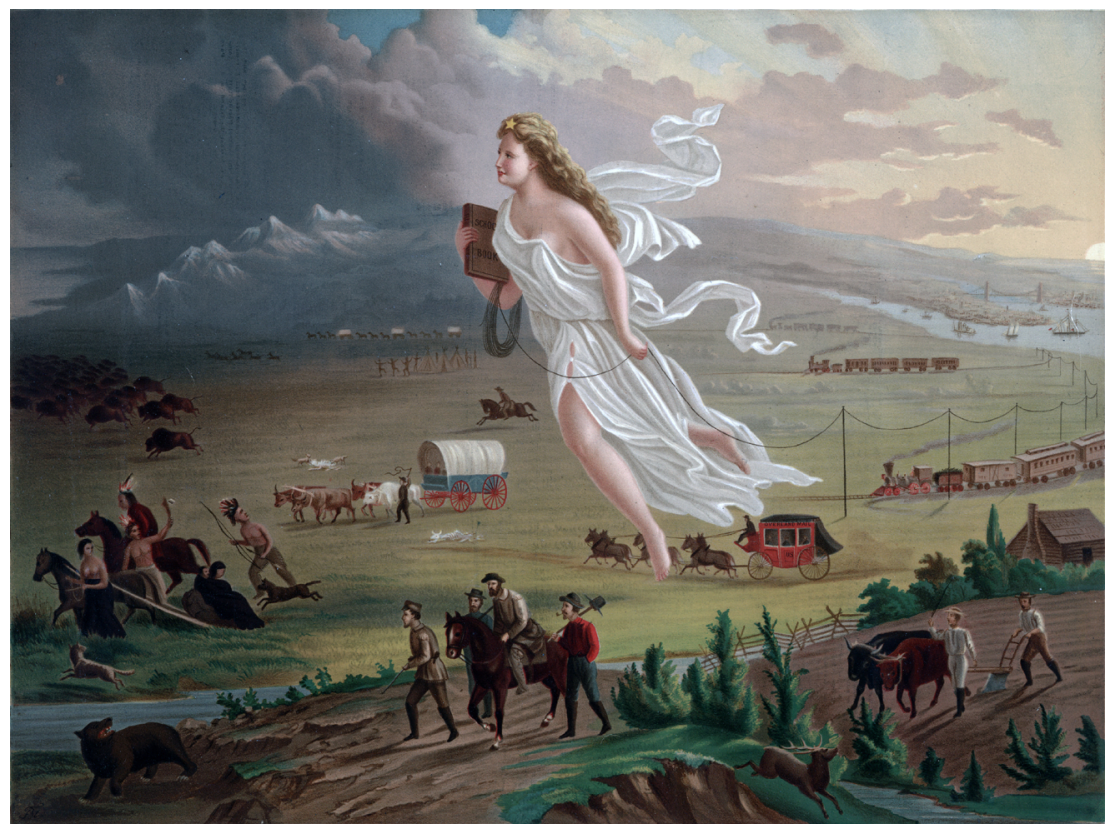

\section{THE GHOST}

In 1872 John Gast painted an image entitled American Progress. In this painting the spirit of America is represented as an angelic blond woman in flowing garments with a star diadem on her head. Hovering over the Midwestern prairie, she gazes confidently westward. Behind her the sun rises on a bustling harbor with a large suspension bridge. Trains and coaches, farmers and prospectors follow the apparition, while in the west storm clouds gather, the bison flee, and the native people cower looking up at this floating giantess.

Thinking about libraries and imperialism, I decided to revisit this painting since it is often thought of as capturing the American idea of Manifest Destiny and, I believe, the idea of White supremacy. As I looked more closely at the foregrounded spirit, I noted that she carries a school book in her right hand and a telegraph wire in her left hand. I thought it was interesting that even in 1872 we see this pairing of printed text and networked information technology. That was the moment I first saw it. You probably see it to. This ghost of imperialism, of Manifest Destiny is a ... librarian. 


\section{CAMPFIRE \#1}

Of course, I don't know if Gast thought of her as a librarian, but she is doing library things, and I'm left to ask why was "American Progress" painted with a textbook and telegraph wire? Why these symbols and this image? What does this phantasm have to say to us about the work we do? Can we create a campfire-like space to lower our shared commitments to librarianship and consider these haunting questions?

I think it is also both fair and important to ask what this painting and story may leave out. Are there aspects of our profession that haven't been represented?

\section{THE INDIGENOUS CONTRAST}

I want to continue to interrogate this painting but shift our attention from the foregrounded White people to the figures in the background. In the distance, Gast painted a cluster of tepees and a group of stick figures with arms and legs akimbo as if in the middle of an ecstatic dance. These figures, and the dance, myth, and tribal customs they suggest were likely meant to be contrasted with the modern knowledge that American progress is bringing.

I asked myself, how do the Indigenous inhabitants of the Americas think about knowledge? How do they seek to preserve and transmit knowledge? As I wrestled with how White supremacy is expressed in librarianship, I conjectured that perhaps exploring Indigenous perspectives on the fundamental tasks that we engage in would help me contextualize the practices of librarianship. Rather than the triumphalism that Gast captures, what if the cultures of Europe and the Americas gathered around a campfire to learn from each other?

I've only begun reading some Indigenous scholars. In the paragraphs below, I want to highlight three key concepts that have stood out to me from what I'm reading. My purpose here is to whet your appetite for thinking about our work from the perspective of different cultures and to invite you to join in this exploration. I'm using the word "Indigenous" to stand in for the great variety of people and cultures that trace their history on this land to times before the Europeans arrived in the fifteenth century. I hope what I offer below can be fruitful for our reflections on the meaning and impact of White supremacy without overstating any particular claim as the Indigenous perspective. 


\section{GROUNDED NORMATIVITY}

Leanne Betasamoske Simpson is a Michi Saagiig Nishnaabeg scholar from the northern shores of Lake Ontario. Her book As We Have Always Done: Indigenous Freedom Through Radical Resistance (Univ. of Manitoba Press, 2017) argues Indigenous identity is formed by their close observation and intimate interaction with a specific place. She uses the phrase "grounded normativity" to capture the way the local land shapes and teaches the Nishnaabeg as they attend to it and its communities (Simpson 2017, 24). The communities in view here are both the biological communities of plants, animals, fish, and people, as well as communities of spirits that are understood to inhabit that place. She writes about land as pedagogy and explains how her people learn how to be in the world through experiencing the rhythms of the physical place where they live.

This emphasis on close observation and participation in the natural world as the source of knowledge stands out to me as a contrast with the rationalism epitomized by thinkers like René Descartes who tried to construct an epistemology that transcended competing claims to truth by suspending belief in the physical world. I also think of how Simpson's focus on understanding the relationships present in a particular location contrast with the project of thinkers like Isaac Newton who sought to discover universal laws that would explain phenomena independent of their local context.

\section{RESEARCH AS RECIPROCAL RELATIONSHIPS}

I really enjoyed reading Shawn Wilson's book Research Is Ceremony (Fernwood Publishing, 2008). Dr. Wilson is Opaskwayak Cree from northern Manitoba, and his book is an example and explanation of an Indigenous research model based on respect, reciprocity, and relationality (Wilson 2008, 77). What stood out to me as I read about Wilson's "3Rs" was that the researcher in this paradigm is always a community member and not a neutral observer. Wilson argues that it is important for the Indigenous researcher to foreground the context of knowing and to situate themselves in spiritual, ecological, and tribal communities. Thus, his academic work on research methodology contains an extended discussion of his parents' life, letters to his children, and personal reminiscences of key sources. 
In addition to the clear contrast with Western traditions of neutrality, I was struck by how little I know about many of the authors that I read and how impersonal the connection between the text and the academic reader often is. The book/reader relationship is often only an intellectual relationship where the author's human reality of being a daughter/sister/mother is obscured at best. The ideas are foregrounded, and the context of those ideas often hidden.

\section{PERFORMATIVE KNOWLEDGE}

The final takeaway thus from my time reflecting on Indigenous knowledge practices was the performative nature of knowledge in indigenous cultures. There is a recurring emphasis on the embodied reception of knowledge that I believe informs Gast's painting of the Native Americans dancing beside the tepees. Ideas of embodied and communal learning also occurred in my conversations with Cher about her experiences in her Native Alaskan village. These ideas are also present in surprising ways in Leanne Betasamoske Simpson's earlier book, Dancing on Our Turtle's Back: Stories of Nishnaabeg Re-Creation, Resurgence, and a New Emergence (Winnipeg: Arbeiter Ring Pub., 2013), where in one memorable passage she talks about how the experience of breastfeeding informs Nishnaabeg politics (Simpson 2013, chap. 6, doc. 92). These ideas of learning with our bodies and from our bodies are not wholly absent in Western thought (reading for example is a physical act), but it does not seem to share a similar place of importance.

In Dancing on Our Turtle's Back, Simpson also talks about the importance of oral storytelling in Indigenous culture-how the formative stories of Indigenous culture are meant to be performed and thus incorporate and interact with the particularities of a given audience and setting (Simpson 2013, chap. 6, doc. 90). There is a dynamism between the elder and the audience that allows for variation and new themes to emerge in old tales. Again, I find some resonance here with the role of academic lecture and sermon that help a new audience find footing in a text, but I am struck by the contrast with how texts are often encountered in libraries where the reader alone bears the burden of understanding the texts' meaning for this moment. I found the reading-room expectation that we acquire knowledge in quiet contemplation to be significantly different from Indigenous ideas of knowledge as performative where we learn 
through song and dance, through attention to our embodied presence in the world, and through participating in the give-and-take of live storytelling.

\section{CAMPFIRE \#2}

As we gather around our second campfire, I wonder: What could we gain from exploring how other cultures, cultures that didn't build libraries, think about knowledge? Would we learn to see ourselves and our work in a different light? Could a change in perspective bring clarity to some of the issues we wrestle with? Alternately, would it complicate things we think are clear?

Given how much there is already to do and learn, how can we either individually or as a profession make space to listen to the experiences of communities that have different starting assumptions, different problems, and different answers? Doing this well would surely take intention, patience, and a level of vulnerability that is uncomfortable.

As I mull this over around my imagined fire, I ultimately wonder if we can make space for the persistence of difference. Can we allow different people to land in different places on questions of epistemology and information best practice? Historically we have struggled to abide this and have fought in more or less aggressive ways to resolve the competition into correct and incorrect ways to proceed.

\section{THESIS}

I want to step back from the campfire artifice momentarily to explicitly state my case. In the first section, I'm suggesting that we seriously consider the possibility that core library norms grow out of European epistemological practices that were used to promote White culture as "civilized" and denigrate other cultures as "savage"-a distinction that gave birth to habits of thought, institutions, and practices that give meaning to the phrase "White supremacy." Furthermore, I think, in the case of libraries, it is possible that this connection informs foundational principles and can't be easily undone.

The claim here is that the library project is morally complex. I don't wish to deny that good has come from libraries as a group or specific libraries and librarians. But I think we need to reflect on the troubling reality that libraries can also be experienced as, and 
can perpetuate, oppression including race-based oppression. I'm encouraged by diversity audits, social justice programming, and other current attempts by libraries to promote equity, but I'm not sure they speak to ways librarianship as an intellectual project is an expression of a particular historic culture and as such share in the strengths and moral failings of that culture.

In the second part, I'm advocating for taking time to learn about the epistemological practices of other cultures. I think that can help us bring into view the way libraries embody the practices of a particular historic community. Libraries thus become contextualized as a way to collect and transmit knowledge, not THE way to do this.

I feel-but ultimately want to warn against-the temptation to seek a synthesis of European and Indigenous American knowledge practices. The facile appropriation of the deep cultural practices of the other do little to promote justice and easily become just another form of colonialism. Rather, I'm hoping that by learning about native communities, I can gain a better understanding of my own culture and traditions. That what I once naively assumed were universal norms may come to be more correctly understood as connected to the history of my culture and my people.

But simply learning about the cultural other, at this late date, seems (and is) an inadequate response to the dispossession and suffering inflicted by the attempt to civilize the other, to say nothing of the attempts to enslave or exterminate those who were deemed less than human. In my final section, I want to look at what theological librarians have to offer as we wrestle with how to move forward.

\section{POTENTIAL CONTRIBUTIONS OF THEOLOGICAL LIBRARIANS}

Many of us in Atla have had advanced training in both librarianship and theology. I think this training positions us to bring to the profession of librarianship theological insights and learning that can assist all librarians in advancing the cause of justice.

I want to begin by talking about humility. It is sadly true that theologians and theological institutions have a very spotty record when it comes to the actual practice of humility. However, reflections on the meaning of humility have been a persistent part of theological discourse and provide rich soil to dig for new language and ideas of how our professional community can understand its work and legacy. 
I have in mind passages like this one, where Paul, writing in Romans, says:

For by the grace given me I say to every one of you: Do not think of yourself more highly than you ought, but rather think of yourself with sober judgment, in accordance with the faith God has distributed to each of you. (Romans 12:3)

In a world that struggles with moral nuance, the command to "think of yourself with sober judgment" primes us to expect complexity. This is just one of many theological texts that wrestle with the inestimable worth and dignity of each human being, but also the moral failings that plague us all. I believe these conversations may provide a helpful guide in thinking about how to affirm what is good and worthy about the work we do while also being able to be honest about our shortcomings.

Second, the trail of victims of White supremacy cries out for a response more substantive than an apology and pledge to do better in the future. Here again I think the centuries of theological reflection on the nature of sin and models of redemption provide a toolkit to help us understand depth of moral pollution and what forms atonement might take. I find it interesting that many people resort to the language of original sin to describe the impact of racism on the United States. Admittedly there are a variety of theological opinions on the nature of sin and atonement that speak to the profound nature of these concepts. But I hold out hope that as libraries wrestle with the taint of White supremacy, theological librarians might be able to offer language and insights from these theological conversations that can provide intellectual footholds for our colleagues and lead to productive reflection on our ways forward.

Finally, religion has long reflected on the nature of hope and renewal and the practices that sustain hope in dark times. I have in mind here the disruptive and generative imagination of the prophet in exile offering not a quick fix, but a vision of a day when the wrongs are made right and the impure will be purified-a time when justice will reign. As we collectively wrestle with the many ways racism is built into the structures and institutions of our society and how endless the struggle for justice seems, I wonder: what insights and practices can we find in our discipline to strengthen and sustain us for the difficult task at hand? 


\section{CAMPFIRE \#3}

I opened by talking about how I often reflect around a campfire on our shared experiences with our most ancient ancestors. As the stewards of the millenniums of religious questions, songs, and conversations, I wonder what aids we may find in our collections. How does our contemporary experience of injustice, suffering, and moral failing connect with those of our forefathers and foremothers? What might we be able to learn from them? In this moment of soul-searching and lament, is there another opportunity to find connections with the larger human story?

\section{SELECT BIBLIOGRAPHY}

Coulthard, Glen Sean. 2014. Red Skin, White Masks: Rejecting the Colonial Politics of Recognition. Minneapolis: University of Minnesota Press.

Gohr, Michelle. 2017. "Ethnic and Racial Diversity in Libraries: How White Allies Can Support Arguments for Decolonization.” Journal of Radical Librarianship 3: 42-58.

Simpson, Leanne Betasamosake. 2017. As We Have Always Done:

Indigenous Freedom through Radical Resistance. Minneapolis, MN: University of Minnesota Press.

-----. 2013. Dancing on Our Turtle's Back: Stories of Nishnaabeg Re-Creation, Resurgence and a New Emergence. Winnipeg: Arbeiter Ring Pub. Nook.

Wilson, Shawn. 2008. Research Is Ceremony: Indigenous Research Methods. Black Point, N.S: Fernwood Pub. 